\title{
Humanitarian and Anthropologic Aspects of Tolerance
}

\author{
Tatiana G. Bekisheva ${ }^{\mathrm{a} *}$, Galina I. Petrova ${ }^{\mathrm{b}}$, S.K. Gural ${ }^{\mathrm{a}}$, Irina V. Brylina ${ }^{\mathrm{a}}$, \\ Alla A. Kornienko ${ }^{\text {, }}$ \\ * Corresponding author: Tatiana G. Bekisheva,bekta74@tpu.ru
}

${ }^{a}$ National Research Tomsk Polytechnic University, 634050, Tomsk, Lenin Avenue, 30, Russia

${ }^{b}$ National Research Tomsk State University, 634050, Tomsk, Lenin Avenue, 36, Russia

\begin{abstract}
http://dx.doi.org/10.15405/epsbs.2017.01.10

The article deals with the problem of tolerance in the prospective of modern information sociality. The method of comparativism makes it possible to find the specifics of the status of this problem at different stages of historical development. Sociocultural approach allowed us extensively consider tolerance as a way of communicative interaction between people (in the biological, social, national, cultural plans). Due to the nature of the modern type of society, its communicative ontology, tolerance is seen as a principle indifferent towards anthropological orientations in the society organization. Tolerance is a social, but not individually personal principle of life interaction between people. However, particularly this indifference gives tolerance possibility to organize society based on democracy, law and ethical norms and to saturate all forms of human interaction with the anthropological content. In this content tolerance has both positive (tolerance is the basis of social democratic regimes) and negative (alienation and disunity of people on a personal level, the crisis of personal identity) sides.
\end{abstract}

C 2017 Published by Future Academy www.FutureAcademy.org.uk

Keywords: Tolerance; anthropology; power; human rights; human well-being

\section{Introduction}

J. Lock introduced the notion and the word "tolerance" as far back as in XVII century, but for humanitarian researches, they presented a special interest only in the end of the twentieth century. The interest came as a result of work with the ground of various kinds of crises that has' become the prerogative of this particular period. Dealing with a crisis ontology the topic of tolerance was generated and the expectation, that acquaintance with the tolerance and the formation of an appropriate thinking and activity may become conditions for human survival in intense crises. In modern international 
community and globalized world space, to find out the specifics of the notion of tolerance, its anthropology and humanity of its content seems relevant.

The problem of the article is caused by the necessity to identify the anthropological content of the notion of tolerance in post-industrial network society when there is an increase in alienation of people. It was found that socio-economic alienation, political alienation and interpersonal alienation were positively related to psychological distress. Resilience was negatively related to psychological distress and it moderated the relationship between socio-economic alienation and psychological distress. Thus, another unique aspect of this study was that we have laid the foundation for the consideration of the moderating role of resilience on the relationship between alienation (and other related variables) and psychological wellbeing (Chuka, 2015).

The phenomenon of an individualism network divides people and does not promote their interaction and unity. At the same time, globalization processes objectively connect all people of the world and make their interconnection necessary. In the following contradictions, expectations are put on the tolerance as the principle of human relations. The question arises: "Is it really tolerance that can solve it and thus provide humanitarian relations and human well-being?" Tolerance seems to be attractive as the principle of social organization has anthropologically rich nature of social relations. Usually this term is associated with the expression of the tolerant attitude, acceptance of the other, communicability. It may seem that all the specified characteristics are humanitarian and anthropological by content (Anikina, 2015). However, keeping in mind that the content of this concept is fundamentally dependent on subjective methods and worldview ideas, from the point of which it is formed, a priori character should be called into question. There are issues related to the understanding and justification of the concept.

The first issue relates to the clarification of the concept of tolerance. The most common understanding of tolerance is the propensity to people, friendly feelings and openness. Can the relationships between spouses be considered as "tolerant" relations?

There may be more question. Moreover, all of them are centered on the specifics of social communications, which by their nature may be either tolerant or, on the contrary, deny this principle in their own organization. Nevertheless, in in both cases tolerance may be called as binding beginning of the sociality, the guiding principle in society design. The presence or absence of this principle has a direct impact on the nature of social relations. In other words, the image of the society is created depending on whether it is generated based on this principle, or this principle is declined. In the first case, it takes on the character of openness and cross-cultural development, democracy in political regime and legal system. The refusal of tolerance creates such social characteristics that are determined in the categories of authoritarianism, totalitarianism, monarchism and so on.

In addition to social, political and economic reasons justifying the concept of tolerance, the causes of a purely philosophical nature should be kept in mind. Paying research attention toward the question of the title is the result of understanding that tolerance today received sanction in the first place from the altered type of philosophical thinking: before becoming a practice of life, tolerance has become a style of thinking. In fact, tolerance is an actual problem today because of the style of thinking, which is caused by the philosophical deconstructive position directed against the recognition of the power of the 
http://dx.doi.org/10.15405/epsbs.2017.01.10

eISSN: 2357-1330 / Corresponding Author: Tatiana G. Bekisheva

Selection and peer-review under responsibility of the Organizing Committee of the conference

classic bases in the philosophy that transmits in various social sectors and practices. Deconstructive processes, first of all, admitted philosophical liberalism that led to the elimination of the power of those metaphysical "limits", "arche", "cells" and "principles" which have been centered philosophy and rigorously provided equally strict centration across cultures and social systems. Modern interest in the revitalization of tolerance as a principle of social construction can be explained by recent changes in philosophy.

The object of study in this article is a general philosophical content of the concept of tolerance. Subject of the investigation is the anthropological aspects of tolerance. The aim is to identify the need for philosophical anthropological aspects of tolerance, including forms of anthropological deficit, the reasons of its presence and the possibility or impossibility of eliminating it at various stages of social history. To achieve the goal the following problems should be solved: the problems associated with the specifics of methodological principles of tolerance research and secondly, the identification of the causes of this anthropologic deficit and justification of the forms of its presence.

In Russian philosophy of communicative ontology positions, and therefore, ontology was Bakhtin M.M. His importance in the global philosophy consists in the fact that in the twentieth century he laid a new dialogical, communicative paradigm of thinking. Methodological attention also causes works of V.S. Bibler, G.S. Batishchev, V.I. Tyupa, and Smirnov I.P. - those who wrote and writes about communication as of those ontology in which frameworks tolerance becomes possible and preferred.

Today the problem of tolerance in Russian literature is developed in the following areas:

- tolerance as a national, interreligious, political, ethnic tolerance (Y.V. Popkov, V.I. Boyko, F.S. Donskoy, V.N. Kozlov);

- tolerance as a cultural dialogue (G.N. Potanin, P.V. Rogovsky, S.K Azbelev, T.F. Kryaklina, E.V. Pomerantseva, K.V. Tchistov, T.A. Kostyukova, T.S. Tyuhtenev);

- tolerance as the principle of historical descriptions (N. Misler, S.A. Ushakin, Ya. Shemyakin, M. Ilyin);

- tolerance as a universal ethical principle (V.M. Zhivov, A.L. Bem, V.N. Ilyin, V.P. Vizgin, V.A. Petrytsky).

Since the late 90 s to the present time, the problem of tolerance has become a leader in the implementation of the Federal target program "Forming Frames of Tolerance and Prevention of extremism in Russian society (2001-2005) and grant works created in different Russia universities.

Much earlier foreign philosophers were engaged in the search for the principle of tolerance and in the specificity of its content. This problem rose in defining the specificity of communicative ontology of social reality (J. Habermas, K. Held, P. Berger and T. Lukman) or in connection with the justification for the introduction of categorical apparatus of the philosophy of "everyday" category (E. Husserl, M. Heidegger, B. Waldenfels). The theme of tolerance and the problem arose in connection with investigations of the new nature of power relations (M. Foucault, P. Bourdieu, J. Habermas and A. Giddens). It is important to emphasize that since the mid-90s of the last century the attention to the problem of tolerance brought the need of its general theoretical development, which stood as the social aspect of the need to answer to the deconstruction of metaphysics (M. Heidegger, J. Derrida, J. Brokmeyer, R. Harps, R. Rorty). Tolerance for Western scientists is presented as a consequence of a 
new stage in the cultural and social development, which is defined as "post-industrial society" (D. Bell), a society of the "third wave" (A. Toffler), "postmodern" (J.F. Lyotard), "open society" (T. Parsons).

\section{Theoretical and methodological approaches to the research}

In order to justify the concept of tolerance, the sociocultural approach is used as research methodology, which takes into account historical, national, cultural and philosophic conditions and forms of their manifestations in different periods of social history.

It is also interesting to ask a question about the biological origins of tolerance for it is believed that as a person in contradiction to the animal does not have the genetic instinctual program "Thou shalt not kill his own kind." Then the tolerance is not its inborn characteristics, it does not have biological roots and it is not essential for him. The logical consequence of these considerations may be presented by the conclusion that the animal kind since it has preserving instinct is essentially tolerant. Although doubt about this answer is obvious, is not it interesting to understand the formulation of the biological origins of the problem of tolerance? Perhaps, could nature take care of the person and give him such a heritage? On the other hand, may tolerance be referred to the number of the acquired social qualities? In this case, what is the socio-historical genesis of this concept?

If we hold the point of view regarding the tolerance as a heritage and care shown by nature relatively to human, it becomes empirically clear that his instinctual genetic program is so weakened and suppressed by reflexive consciousness that in the case of tolerance (as in other cases) it does not detect its serious importance in terms of the behavior determinants. "Man - is the one who can say "no" to "nature" the ascetic of life, "- writes in this regard the founder of philosophical anthropology Max Scheler (2008). Then Scheler goes on: being expelled from the womb of nature, he gets an oddity existence and goes out of the evolutionary chain of natural life, interrupts it, and this is a deadlock in its vital definitions. "The new principle that makes a man human is beyond all that in the broadest sense, with an internal psychic or vital external part we can call life. What makes us human being, is the principle, the opposite of all life at all, it itself cannot be reduced at all to the natural evolution of life." (Scheler, 2008). However, apparently because the person was "dead end of life" - a life of vitality - he had to find "a great exit", which consisted in the fact that he has acquired another - not natural - way of being. Human life becomes "bigger-than-life" (Simmel, 2010), because he transcends its natural order, and breaks it out into oddity, trans-vital existence.

Trans-vitality is an overrun from the vital framework where life is understood in its purely biological sense and where self-preservation instinct determines the all its other manifestations. Transvitality absorbs social and spiritual, purely human characteristics of life. Human life, therefore, turns out to be more life than its biological manifestations. In this sense, it becomes a "larger than life". Biology at the human level is saturated with the spirit that transforms animal nature and informs the person about oddity existence. Among the purely human characteristics reflection is perhaps, the main one since it allows discovering its meaning to all other specific features of human existence. Due to reflection and reflexive consciousness, the man - not only is (exists), but also knows about himself that 
http://dx.doi.org/10.15405/epsbs.2017.01.10

eISSN: 2357-1330 / Corresponding Author: Tatiana G. Bekisheva

Selection and peer-review under responsibility of the Organizing Committee of the conference

he is. Having acquired this knowledge, he by himself (and not by nature) takes care of himself, creates life program, having ability and opportunity to overcome natural (instinctual) program.

In this human understanding lies the answer to the question of natural indifference to him and about the reasons of his genetic program lack, "Thou shalt not kill his own kind." The answer is that man is able to create such a program himself. It becomes a part of the formation of tolerance as a social program, which is generated by human under the influence of specific social and historical conditions of life and finds itself in the forms of human consciousness, behavior and activity. Agreement with this thesis largely explains why the theme of tolerance becomes relevant precisely today - in the age of information and informational communications.

Liberalization of philosophical knowledge, that is, the proposal of self-organizational communication (instead of centralization) as a social ontology resonantly responded in various spheres of culture - in the power and legal culture. It enables the relevant legitimation of nonviolence in politics, ethnic relations, ideology, and so on. Modern culture is no longer built on the foundation of a single principle - "arche", in the form of which previously could be transcendental community of substance, such as "natural right" P. Gobbs, J.J. Russo or the absolute idea of Hegel or the substance immanent nature, such as industrial relations of Marx or "a social action" of M. Weber. Modern culture is based on many different principles. Rejection of basic, all causing structure makes it tolerant, draws attention to the whole range of social relations, their clutches and their communication.

The deconstruction of the metaphysical "arche", performing in the tradition of philosophical thinking style as the center of philosophy resonantly responded in various spheres of social life. Society as a social reality has acquired communicative ontology. It has changed conceptual content of the basic structures of sociality, such as power and law. The power based on the subordinate relationship has disappeared because there is a new picture of sociality and culture, where the hierarchy of power structures gave way to political democracy, marked on the philosophical language in terms of "communication", "everyday life", "life world." Of course, all these facts testified that positive changes have occurred in the principle of tolerance, which organizes communicative ontology of selforganization developing society towards the adoption of democratic political systems. Thus, it would be possible to draw a conclusion regarding that tolerance bears the anthropological contents. Is it so?

\section{The concept of tolerance and anthropological deficit is tolerant to the organized sociality}

What anthropological content does the new nature of social reality mean - not hierarchically, but communicatively and tolerantly constructed? The question arises in connection with the fact that in the communicative "space of flows" (Castells, 1996) a man was not centered in logically arranged reality, but in self-geterohierarchical sociality. Thrown in the unstable world of movement and unpredictability of communications, kaleidoscopic unpredictable turnover of configurations of communicative image, rhizome in the areas of development, he found himself overwhelmed by streams of rapidly changing information, lost communication in the world, acquired the character of the textual "sign", "track" "numbers". In such ontology, a living human content is deprived from social reality. Moreover, in the ever-changing interweaving of various forms of activities, professional areas and information flows it 
turns into constantly creating and recreating construct. The number plate replaces living person; he becomes a pragmatic-minded agent.

Perhaps for the first time the "death of a man" was spotted by Michel Foucault. As he wrote, nowadays one can only think in the empty space, where there is no human..." For all those who still want to talk about the man, his kingdom and release to all those who still want to ask questions about what man is in his essence, to all those who want to come out of a man in his search for the truth, and on the contrary to all those who reduces all cognition to the truths of a man ... who does not want to think at all that it is a man who thinks - a philosophical laughter can be opposed to all these absurdities and absurd forms of reflection, that is, in other words, the silent laughter" (Foucault, 2002). He wrote, "You can guarantee - a man will disappear like an inscribed face disappears from the sand" (Foucault, 2002).

The conclusion arises, that sociality which refused from the center of power and was based on tolerant communication, turns out to be the sociality of a man-mark. Its natural dimension is lost. Marks without referents replaced its living anthropological contents. It is no longer based substantially: corporal substance, in the form of the material production as a basis for the development of society is also destroyed. Hegelian's "World Spirit" has gone, which had a claim to the construction of both society and nature, the substantial design principle has gone by itself. Only communication has left.

Communicative ontology builds up on the principle of tolerance, because it releases the "productive force" of communication. "Instead of relying on the mind of the productive forces, that is, finally, on the mind of natural sciences and engineering, I trust the productive force of communication", writes J. Habermas (1995). Communications create a situation of equality of all social structures without the possibility of any priorities. Nevertheless, as a principle of organization of tolerance, it has created not living, spiritual and emotionally social organization, but the atmosphere of soulless and impersonally cold communication.

It must be noted that philosophical thought in the course of their own history has played a significant role in this transformation because, looking for a person, it has subordinated him to its general principles of constructing the truth, and erected him to the universal essence - eternal, stable, absolute. In this specificity, it transformed him into the subject. It was convenient to work with a human-subject: the subject of law, the subject of economy, political subject - constructs that reduce human uniqueness and originality, which allowed equalizing everybody in communicative and tolerant principles. A man in tolerant communications is the subject, the idea of a rational person is the idea of total, absolute and so that it is deprived of living human content.

The conclusion seems to be unexpected and paradoxical. Tolerance is the structure that was expected to be the main saturation for anthropological culture. Tolerance is an acceptance of the other person, embracing him, it is love, freedom, equality but suddenly it turns out to have a cold face, it seems to be abstractive from human ideas. In fact, it is tempting to agree with the conclusion that tolerance - is soulless and impersonal, deprived of human content principle of formal organization of society, which transforms a man into an agent or "actor" of social relations. However, if there is no socio-cultural, vital, anthropological warmth, what makes the idea of tolerance to be attractive? 
The problem of humanitarian and anthropological content of tolerance is not among the developed ones. Ambitions and expectations associated with this principle, forced to look at tolerance, communication, democracy in humanistic and anthropological contexts. Equality, solidarity, democracy - all these seem to be an objective social consequence of tolerance, filled with anthropological content. However, is it really so?

In fact (and this is the deductive premise for further considerations) the principle of tolerance in its action is effective in terms of democratic and humanistic nature of sanctions only because it deprived of anthropological, that is human, existential content. Conclusion is paradoxical, but it is justified by a rational nature of tolerance, which in its turn causes the relationship of rational nature of all structures of sociality - law, power, economics, and culture as a whole. Democratic power is strictly regulated by law, the rights and human responsibilities for a man as a social subject, but not as a living human being. Could the power focus on the uniqueness of every person? A negative answer is obvious: each person is unique. The power law cannot be calculated objectively in the circumstances of the precedent, it is only a generalized rational design. What is the solution? Should we consider tolerance as a false principle of social organization? On the other hand, is it possible to recognize this principle as a social truth?

The answers to these issues are of theoretical interest, since they are based on current changes in the style of philosophizing, and they objectively lead to the possible reconsideration of the problems of concrete sciences, executed by appropriate social practices. First, the question is about the leading practice and science for the society, for example, such as law and legal science, the power and the state, education and pedagogics. All of them have an explicit anthropological orientation and their content should be explicitly anthropological as well. Their review in relation to the changes that are now experiencing the culture of philosophical thinking is in the form of actualization the discussion of relevant areas of knowledge and practice. Therefore, in terms of the philosophical thinking of modern style it would be interesting to prove the possibility of reconsideration. For example, the concept of law in the direction of liberalization of its content, opportunities for the legal decisions, to pay attention to the issue of precedent and the alibi of the committed acts, given the context of their implementation and the identification of the individual circumstances while passing the sentences.

Of course, coming from the philosophy of such proposals, if implemented many questions are related to the possible legalization of disobeying rules, laws, rights an justification of denying the duties. However, they rise and they can be discussed. The context of the discussion was formulated by the philosophy when it has liberalized semantic heterogeneity of pluralism and has put it into place of the last rational homogeneity of truth. New - desubstantsializing social reality is constructed by illogical way, unstable in constant motion and are not projected in the endless changes, was the successor to its previous state, built for the subject as a rational anthropological structure. The processes that have taken place in philosophy, made certain changes in the social structure. For example, a social subject has given way to social agents (the man as the subject of today is replaced by a human-agent). Nevertheless, is there an evidence of humanitarian turn in understanding of a man? 
This question makes it necessary a reflection, concerning the law, power, and other social institutions and reconsideration of them in the context of the humanitarian opportunities that provided non-classical style of philosophical thinking.

Reconsideration is associated with the understanding that the society where formal communication and impersonal information dominate, human orientation is lost and it is neutral both to violence, authoritarianism and totalitarianism and to tolerance, love, location, and so forth. The neutrality causes strictly rational principle of its organization that is tolerance. The objective of this is the result of a stable democracy, the freedom of interaction, the ability to search for agreement, while maintaining the various positions and angles. Tolerance does not associate itself with the mandatory acceptance of another person, love for another or building somebodies loyalty; it moves away from all the emotional and sensual, empathy parties in the relationship. Tolerant relationships are always communicatively rational and rely only on the "productive force of communication" (Habermas, 1995), they suggest the rejection of force impact and violence. Only in communications, according to Habermas, you can look for "consent". The author rises the category of the consent to the level of categorical apparatus of philosophy. Tolerance, harmony, communication are phenomenon of the same order.

\section{Conclusion}

The historical conformity is that authoritarianism and totalitarianism correspond to traditionalist types of society. This contributes to their hierarchical organization, the rigidity of power relations, their transfer by inheritance, caste character, stability of social structures and their reproduction in the development. Tolerance is a democratic prerogative of sociality, which denies the relationships based on power or violence in all forms of their manifestation accepts and implements the idea of freedom of the sociocultural world. However, in the practice of tolerant relations it is necessary to keep in mind neutrality and soulless of the tolerant principle, its disregard for the living human beings. Tolerance is not interested in originality and uniqueness of the personality. The interest of this principle is addressed to the social structure as a form, but not as to its living human content.

\section{Acknowledgements}

The work reported here is sponsored by National Research Tomsk Polytechnic University and National Research Tomsk State University.

\section{References}

Anikina, E., Ivankina, L. \& Tumanova, I. (2015). Human Well-being and Educational Investment Efficiancy. Procedia - Social and Behavioral Sciences, 166 (7), 48-52.

Castells, M. (1996). The Rise of the Network Society. The Information Age: Economy, Society and Culture, 1. Cambridge, MA; Oxford, UK: Blackwell.

Chuka, M., JohnBosco, C., Endurance, A. (2015). Alienation and Psychological Wellbeing: Moderation by Resilience. Social Indicators Research Journal, 120 (2), 525-544.

Foucault, M. (2002). The order of things - an archaeology of the human sciences. London/ New York: Routledge Classics. 
http://dx.doi.org/10.15405/epsbs.2017.01.10

eISSN: 2357-1330 / Corresponding Author: Tatiana G. Bekisheva

Selection and peer-review under responsibility of the Organizing Committee of the conference

Habermas, J. (1995). Democracy. Reason. Morality. Moscow lectures and interview. Moscow: JSC KAMI, Publishing center ACADEMIA.

Scheler, M. (2008). The Human Place in the Cosmos. Northwestern University Press.

Simmel, G. (2010). The View of Life: Four Metaphysical Essays with Journal Aphorisms. Chicago: University of Chicago Press. 